\title{
2020 Dr. Pedro Cossio Foundation Award
}

\author{
Premio Fundación Dr. Pedro Cossio 2020
}

JORGE LERMAN

President of the Jury

The 45th Congress of our Argentine Society of Cardiology was held on November 19-21, 2020. Like almost all of what happened during this very special year, it was a completely new experience. The Organizing and Scientific Committees had to reinvent themselves and move this large-scale onsite congress to a virtual event using the different tools provided by computer technology. Instead of having direct contact with the speakers, the Jury accessed the recorded version of each presentation, without the contribution of expert commentators on the various topic areas.

The Scientific Committee of the Congress selected 6 works to contend for the 2020 Dr. Pedro Cossio Foundation Award. Following the tradition installed 32 years ago, we shall make brief comments about the works selected.

The winning work was:

Association between inflammatory interleukins and intraventricular conduction disturbances in patients with positive serology for Chagas disease and preserved ventricular function.

Mario Principato, Analia Paolucci, Silvia Miranda, Gustavo Sosa, Maria Von Vulffen, Alejandro Tomatti, Guillermo Di Girolamo, Justo Carbajales

In addition to the direct damage caused by the parasite, there is evidence of immunological and inflammatory activity in the pathophysiology of Chagas disease (CD). Forty years ago, Dr. Patricio Cossio, one of the sons of the prestigious cardiologist after whom this award of the Argentine Society of Cardiology is dedicated, performed pioneering studies in this field. (1)

More recently, IgG antibodies against muscarinic M2 receptors have been identified to be responsible for bradyarrhythmias and atrioventricular conduction disturbances. (2) $\beta 1$ and $\beta 2$ adrenergic receptor autoantibodies can be produced by patients with $C D$ as was previously demonstrated by the authors of the group that conducted this study. $(3,4)$ These autoantibodies, originally targeted against the parasite, would recognize host antigens. Moreover, inflammatory cytokines can also damage myocardial tissue and cause ventricular dysfunction in this disease. (5)

The objective of this study conducted at Hospital
Ramos Mejía of Buenos Aires and Instituto Alberto C Taquini de Investigaciones en Medicina Traslacional was to investigate whether systemic inflammation could be associated with the development of intraventricular conduction disturbances (IVCD) in early stages of CD. The study included 22 patients between 21 and 80 years of age with positive serology for CD and left ventricular ejection fraction $\geq 50 \%$. These patients were compared with a control group of 14 healthy individuals with similar age and male-to-female ratio, and negative serology for CD. The plasma concentration of several markers of inflammation was measured and the presence of IVCD -right bundle branch block, left bundle branch block or left anterior hemiblockwas analyzed. Ten of the 22 patients had IVCD. These patients had significantly higher levels of interleukin $10,2,12 \mathrm{p} 70,15, \mathrm{INF} \gamma$ and MP1 $\alpha$ than those without IVCD. Patients with IVCD were older $(61.3 \pm 13.3$ vs. $50.9 \pm 6.2$ years) and had lower left ventricular ejection fraction $(59.6 \% \pm 6.2$ vs. $62 \% \pm 7.0)$ than those without IVCD. These differences were not significant probably due to the small sample size. Furthermore, cytokine levels in patients without ICVD were similar to those of controls. These results demonstrate a novel finding that should be reconfirmed by larger studies: CD patients with preserved left ventricular function and IVCD have higher levels of proinflammatory cytokines.

The other works were:

Lipoprotein (a) in the general population with moderate cardiovascular risk and increased LDL cholesterol. What is the prevalence and association with history of premature cardiovascular disease?

Pablo Gulayin, Alfredo Lozada, Laura Schreier, Laura Gutiérrez, Graciela López, Matías Calandrelli, Fernando Lanas, Vilma Irazola.

This new report of Centro de Excelencia en Salud Cardiovascular para el Cono Sur (CESCAS) is another contribution of the same group whose studies had been selected in previous versions of this award and resulted winner in 2017.

Lipoprotein(a) or $\mathrm{Lp}(\mathrm{a})$ consists of one cholesterol-rich LDL lipoprotein molecule attached to an apolipoprotein(a) molecule via a disulfide bond. 
Apolipoprotein(a) possesses structural homology with plasminogen, producing its competitive inhibition, and consequently blocking its fibrinolytic activity. Thus, Lp (a) has prothrombotic and anti-fibrinolytic effects. In addition, $\operatorname{Lp}(\mathrm{a})$ can easily cross the endothelium and contribute to the development and growth of atherosclerotic plaques. This double mechanism makes $\operatorname{Lp}($ a) a novel risk factor for atherosclerotic disease, particularly in the coronary arteries, which is not yet considered in the different risk scores known. (6)

The aims of this study were: 1) to evaluate the prevalence of elevated $\mathrm{LP}(\mathrm{a})(>125 \mathrm{nmol} / \mathrm{L})$ in the general population with moderate cardiovascular risk (between 10\% and 20\%) and elevated LDL cholesterol (>130 $\mathrm{mg} / \mathrm{dL}$ ); and 2) to determine the association between family history of premature cardiovascular disease (FHCVD) and elevated LP(a) in individuals of 4 cities in the Southern Cone of Latin America: Marcos Paz and Bariloche (Argentina), Canelones (Uruguay), and Temuco (Chile). The sample included 7524 subjects (2165 men) between 35 and 74 years. Among the total population, about $11 \%$ had FHCVD and $6.1 \%$ presented elevated $\mathrm{Lp}$ (a) levels. The most significant finding of this study was that in subjects with LDL cholesterol $\geq 160 \mathrm{mg} / \mathrm{dL}, \mathrm{LP}(\mathrm{a})$ was elevated in $5 \%$ of cases without FHCVD and in $18 \%$ of those with FHCVD ( $p=0.026)$. This work confirms the strong genetic association of elevated LP(a) and shows that asking a simple question about family history in patients with elevated LDL cholesterol could contribute to identify subjects with elevated levels of this new risk factor that is not very commonly investigated but has a strong impact on the natural history and prognosis of atherosclerotic disease.

Hyperaldosteronism has prognostic implications in patients with pulmonary hypertension and adequate functional class

Andrés Atamañuk, Jorge Zambrano, Ignacio Gandino, Diego Hoffmann, Rafael Zaug Nadur, Sebastián Obregón, Luis Gómez, Diego Litewka

The renin-angiotensin-aldosterone system (RAAS) is one of the basic humoral mechanisms with multiple involvement in the development and progression of systemic hypertension and heart failure. Vasoconstriction with increased afterload, sodium retention with increased preload, and vascular and left ventricular remodeling are the most important and wellknown processes in which RAAS participates, and its inhibition is one of the mainstays of the treatment of these conditions. (7) The activation of RAAS in pulmonary hypertension $(\mathrm{PH})$ is less explored but could have prognostic implications. (8)

The authors of the present study, from the Hospital Fernández of Buenos Aires group, conducted a prospective, observational study of patients with $\mathrm{PH}$ diagnosed by right heart catheterization. They analyzed 38 patients (36 women) with stable $\mathrm{PH}$ in functional class (FC) I or II. Plasma aldosterone (PA) levels, plasma renin activity (PRA) and the PA/PRA ratio were assessed. The aim of the study was to identify the presence of hyperaldosteronism (HA) in $\mathrm{PH}$ and its prognostic implication. Hyperaldosteronism was defined as PRA $<1 \mathrm{ng} / \mathrm{mL} / \mathrm{h}$ and $\mathrm{PA} / \mathrm{PRA}$ ratio $>20$; elevated PA >90 pg/mL; and low PRA <1 ng/ $\mathrm{mL} / \mathrm{h}$. The distance achieved in the 6 minute-walk test (6MWT) and NT-proBNP levels were analyzed as prognostic factors.

Patients with HA had lower PRA: 0.29 \pm 0.01 vs. 1.26 \pm 1.1 ( $\mathrm{p}<0.043)$ and higher $\mathrm{PA} / \mathrm{PRA}$ ratio: $35.9 \pm 11.8$ vs. $8.9 \pm 5.0$ ( $\mathrm{p}<0.001)$. The distance walked in the 6MWT was lower: $343.5 \pm 101$ vs. $445.6 \pm 83 \mathrm{~m}(\mathrm{p}=0.012)$ and NT-proBNP levels were higher: $1602.2 \pm 1492$ vs. $562.7 \pm 854 \mathrm{pg} / \mathrm{mL}(\mathrm{p}=0.022)$. These indirect signs suggest that the prognosis could be worse in patients with $\mathrm{PH}$, adequate or moderately symptomatic and HA. These preliminary changes should be confirmed in a larger study with a control group without $\mathrm{PH}$ and long-term follow-up.

Does high-sensitivity cardiac troponin add prognostic value to validated risk scores to predict in-hospital mortality in patients with acute heart failure?

Lucrecia Burgos, Lorena Villalba, Rita Miranda, Andreína Gil Ramírez, Luján Talavera, Adriana Acosta, Fernando Botto, Mirta Diez.

High-sensitivity cardiac troponin $\mathrm{T}$ (hs-cTnT) is a useful marker in emergency departments and coronary care units for the diagnosis of acute coronary syndromes. However, there is poor evidence about its role in the diagnosis and prognosis of acute decompensated heart failure (ADHF).

The aim of this study was to determine if the addition of hs-cTnT to clinical risk scores improves their performance to predict in-hospital mortality in patients with $\mathrm{ADHF}$. A retrospective analysis was conducted of a prospective cohort of consecutive patients from Instituto Cardiovascular de Buenos Aires. The study included 712 adult patients hospitalized between 2015 and 2019 with a primary diagnosis of ADHF. Mean age was $74.8 \pm 12.5$ years and $64.1 \%$ were men. Left ventricular ejection fraction (LVEF) was reduced $(<40 \%)$ in $47.8 \%$ of patients. The most common reason of decompensation were dietary transgressions, infections and supraventricular tachyarrhythmias. Three validated and widely used risk scores were calculated: OPTIMIZE-HF, GWTG-HF and ADHERE. hs-cTnT was measured in $79 \%$ of the population and was elevated in $91 \%$ of cases. The primary endpoint was in-hospital mortality. The authors performed a sub-analysis according to LVEF. The discrimination performance was evaluated with the area under the ROC curve (AUC-ROC).

In-hospital mortality was $8.7 \%$. The AUC-ROC $(95 \% \mathrm{CI})$ for isolated hs-cTnT was $0.70(0.63-0.77)$, and 0.80 (0.74-0.87), $0.79(0.72-0.86)$ and 0.79 (0.71-0.86) for the OPTIMIZE-HF, GWTG-HF and ADHERE scores, respectively. Adding hs-cTnT to the models did not increase the AUC-ROC: 0.72. The sub-analysis did 
not demonstrate differences in the risk scores after adding hs-cTnT in the population with LVEF $<40 \%$ and $\geq 40 \%$. In conclusion, elevated hs-cTnT on admission was common and its incorporation into validated risk scores did not provide an additional benefit to predict the outcome in these patients. These results could be explained by the high prevalence of hs-c TnT in the population analyzed and the relatively low frequency of ischemic etiology, since hs-cTnT is basically a marker of necrosis and, the ischemic etiology was not one of the most common in these patients.

Clinical outcome and prognosis of a population of patients with nonobstructive hypertrophic cardiomyopathy

María Banchio Dal Bo, Nahuel Messina, Alejandro Quiroga, Guido Antoniutti, José Horacio Casabé, Juan Mouzarkel, Luis Verón, Adrián Fernández

Most patients with hypertrophic cardiomyopathy present the obstructive type of the disease (70\%) defined as the presence of a left ventricular outflow tract pressure gradient $\geq 30 \mathrm{mmHg}$ at rest or induced by the Valsalva maneuver or after exertion. Patients with nonobstructive hypertrophic cardiomyopathy (NOHCM) experience a largely stable clinical course at relatively low risk for progressive heart failure (HF) symptoms or serious arrhythmias. (9)

This group of Fundación Favaloro conducted a retrospective and observational study of 225 consecutive patients with NOHCM between 1993 and 2020 (mean age was $45 \pm 16$ years and $69 \%$ were men). The primary endpoints were sudden cardiac death (SD) or appropriate implantable cardioverter defibrillator (ICD) shocks considered as surrogate for SD, and death due to $\mathrm{HF}$ or need for heart transplantation considered as surrogate for death due to HF. The secondary endpoint was the presence of atrial fibrillation. Five patients $(3 \%)$ presented severe mitral regurgitation. Despite the absence of significant obstruction, 22 patients $(14 \%)$ presented systolic anterior motion of the mitral valve, demonstrating that it can be produced by multiple mechanisms and cannot be attributed solely to the obstructive gradient. After a mean follow-up of 7.5 years, 17 patients $(7.6 \%)$ developed the primary endpoint and $69(31 \%)$ the secondary endpoint. Moreover, 9 patients (4\%) evolved with LVEF impairment during follow-up and 4 (2\%) required heart transplantation. An ICD was implanted to 50 patients $(22 \%)$. This study provides an interesting observation that illustrates the echocardiographic characteristics and clinical course of patients with NOHCM. Although it is generally considered a relatively benign condition, complications may occur in the mid-term. Therefore, these patients require appropriate follow-up. The use of magnetic resonance imaging to identify fibrosis by late enhancement contributes to categorize highrisk patients, while genetic tests may identify family groups.

Do ultrasound lung comets represent an improved concept of congestion and variability in heart failure?
Lilia Princich, Nadia Vergara, Ezequiel Besmalinovich, Agustina Rossi, Paul Vargas Mieles, Christian Musante, Romina Caprini, Adrián Lescano

Lung ultrasound (LU) in heart failure (HF) is a useful tool to detect and evaluate pleural effusion. Another indication is for the evaluation of lung congestion, extravascular interstitial-alveolar fluid, and response to treatment by observing "lung comets" (LC). However, this last indication is rarely used and was performed in $9 \%$ of cases in the ARGEN-IC registry. (10) Lung comets represent Kerley's B lines on chest X-rays and are observed, by placing the ultrasound probe perpendicular to the chest wall, as thin, dense lines that arise from the pleural line to reach the end of the screen; i.e. they are dynamic and move with pleural sliding.

This work presented by Sanatorio de la Trinidad de Quilmes included 49 patients with $\mathrm{HF}$, mean age of $70 \pm 14$ years and $73.4 \%$ men. Eighty percent had hypertension, $46 \%$ diabetes, $25 \%$ had a history of myocardial infarction, $23 \%$ had significant valvular heart disease and $36 \%$ had atrial fibrillation. On admission, $\mathrm{HF}$ presented as lung congestion in $29 \%$ of cases, peripheral congestion in $11 \%$, mixed congestion in $44 \%$ and acute pulmonary edema in $16 \%$. LVEF was severely reduced in $58 \%$ of patients, moderately reduced in $20 \%$ and preserved in $22 \%$. Ninety-one percent of patients presented LC on lung ultrasound (27.3 \pm 11.17 ). The number of LC between admission and discharge was significantly reduced $(27.3 \pm 11.17$ vs. $5.27 \pm 4.14 \mathrm{p}=0.0001)$. In contrast, there were no significant changes in ejection fraction, echocardiographic dimensions, mitral inflow estimated by $\mathrm{E} / \mathrm{e}$ ' ratio or in the small subgroup (23\% of cases) in which NT-proBNP was measured. The authors concluded that LC are observed in a high proportion of $\mathrm{HF}$ patients and, despite the small sample size, they were the only marker that showed significant variability associated with treatment during hospitalization. When a patient is admitted with acute $\mathrm{HF}$ and receives the corresponding treatment during hospitalization, the need to continue with diuretics after discharge and the dose required may be unclear. Serial screening of LC provides an objective approach that is readily available and simple to determine the severity of pulmonary congestion and to evaluate treatment effectiveness.

The jury of the 2020 Dr. Pedro Cossio Foundation Award was formed by the former presidents of the Argentine Society of Cardiology, Dr. Miguel González and Dr. Osvaldo Masoli, to whom I am grateful for their skilled and responsible participation.

\section{REFERENCES}

1. Cossio PM, Diez C, Laguens RP, Arana RM. Inmunopatología de la Enfermedad de Chagas. Medicina (Buenos Aires) 1980; 40 (Supl. 1): $222-30$

2. Thiers C, Barbosa J, Pereira B, Nascimento E, Nascimento J, 
Medei E, et al. Autonomic dysfunction and anti-M2 and anti- $\beta 1$ receptor antibodies in Chagas disease patients. Arq Bras Cardiol. 2012;99:732-9. https://doi.org/10.1590/S0066-782X2012005000067 3. Rosenbaum M B, Chiale P A, Schejtman D, Levin M, Elizari M V. Antibodies to Beta-Adrenergic Receptors Disclosing AgonistLike Properties in Idiopathic Dilated Cardiomyopathy and Chagas' Heart Disease. J Cardiovascular Electrophysiol 1994;5:367-75. https://doi.org/10.1111/j.1540-8167.1994.tb01174.x

4. Chiale P A, Rosenbaum M B, Elizari M V, Hjalmarson A, Magnusson Y, Wallukat G, et al. High Prevalence of Antibodies against Beta 1- and Beta-Adrenoceptors in Patients with Primary Electrical Cardiac Abnormalities. J Am Coll Cardiol 1995;26:864-9. https://doi.org/10.1016/0735-1097(95)00262-2

5. Rodrigo Sousa G. Plasma Cytokine Expression Is Associated with Cardiac Morbidity in Chagas Disease. PLoS One. 2014;9(3): e87082. https://doi.org/10.1371/journal.pone.0087082

6. Nordestgaard BG, Langsted A. Lipoprotein (a) as a cause of cardiovascular disease: insights from epidemiology, genetics, and biology. Journal of lipid research 2016;57:1953-75. https://doi. org/10.1194/jlr.R071233

7. Pitt B, Zannad F, Remme WJ, Cody R, Castaigne A, Perez A, et al. The effect of spironolactone on morbidity and mortality in patients with severe heart failure. N Engl J Med. 1999;341:709-17. https:// doi.org/10.1056/NEJM199909023411001

8. Maron BA, Leopold JA. The role of the renin-angiotensin-aldosterone system in the pathobiology of pulmonary arterial hypertension (2013 Grover Conference series). Pulm Circ. 2014;4:200-10. https://doi.org/10.1086/675984

9. Maron BJ, Rowin EJ, Maron MS, Braunwald E. Nonobstructive Hypertrophic Cardiomyopathy Out of the Shadows: Known from the Beginning but Largely Ignored ... Until Now. Am J Med. 2017; 130:119-23. https://doi.org/10.1016/j.amjmed.2016.09.015

10. Lescano A, Soracio G, Soricetti J, Arakaki D, Coronel L, Cáceres L et al. Registro Argentino de Insuficiencia Cardíaca Aguda (Argen IC). Evaluación de cohorte parcial de 30 días. Rev Argent Cardiol 2020;88:118-25. https://doi.org/10.7775/rac.es.v88.i2.17201 